\title{
Effects of inundation duration on southeastern Louisiana oyster reefs
}

\author{
Danielle A. Marshall ${ }^{1}$ (D) and Megan K. La Peyre ${ }^{2}$ (D) \\ ${ }^{1}$ School of Renewable Natural Resources, Louisiana State University Agricultural Center, Baton Rouge, LA 70803., and ${ }^{2}$ U.S. \\ Geological Survey, Louisiana Cooperative Fish and Wildlife Research Unit, School of Renewable Natural Resources, Louisiana \\ State University Agricultural Center, Baton Rouge, LA 70803. \\ ${ }^{*}$ Corresponding author: Email: MLapeyre@agcenter.lsu.edu
}

(Received 24 March 2020; Revised 15 July 2020; Accepted 15 July 2020)

\begin{abstract}
Understanding the effects of predicted rising sea levels, combined with changes in precipitation and freshwater inflow on key estuarine ecosystem engineers such as the eastern oyster would provide critical information to inform restoration design and predictive models. Using oyster ladders with shell bags placed at three heights to capture a range of inundation levels, oyster growth of naturally recruited spat was monitored over the course of 6 months. Oyster numbers and shell heights were consistently highest in bottom and mid bags experiencing greater than 50\% inundation (mid: $63 \pm 7 \%$; bottom: $95 \pm 3 \%$ ). Identifying thresholds for optimal oyster growth and survival to enhance restoration engineering would require finer scale evaluation of inundation levels.
\end{abstract}

Keywords: Crassostrea virginica; reef exposure; oyster growth

\section{Introduction}

Oyster reef restoration is increasingly used as a tool to ameliorate the negative effects of overharvesting and habitat degradation (Blomberg et al., 2018). In Louisiana, eastern oyster (Crassostrea virginica) reefs provide extensive habitat (La Peyre et al., 2019), and support a valuable industry (NOAA, 2020). These oyster populations thrive in Louisiana's estuaries, and exist both inter- and sub-tidally, but restoration projects struggle to identify inundation thresholds for designed reefs. With changing sea levels and variation in reef elevations, understanding how inundation time might affect oyster growth, survival and reef sustainability is critical (Ridge et al., 2015; Solomon et al., 2014). The threshold between a successful or failed restoration may be a matter of centimeters (Fodrie et al., 2014) with increased inundation time often resulting in biological stressors (i.e., increased predation and biofouling), and reduced inundation time resulting in increased abiotic stressors (i.e., desiccation; Bishop \& Peterson, 2006).

\section{Objective}

The objective of this study is to use oyster ladders (e.g., Solomon et al., 2014) to monitor the effects of inundation duration on oyster growth, with bags of oyster substrate (i.e., shell) placed at different heights to capture varying inundation levels.

\footnotetext{
(c) The Author(s), 2020. Published by Cambridge University Press. This is an Open Access article, distributed under the terms of the Creative Commons Attribution licence (http://creativecommons.org/licenses/by/4.0/), which permits unrestricted re-use, distribution, and reproduction in any medium, provided the original work is properly cited.
} 


\section{Methods}

Oyster ladders were constructed of $\sim 50 \mathrm{~mm}$-wide, $\sim 3 \mathrm{~m}$-tall PVC driven into the soils at least $1 \mathrm{~m}$, with cables at three levels off the water bottom to target different inundations (top, mid, bottom, $40 \mathrm{~cm}$ difference in levels; Figure 1). On April 9th, 2018, ladders were deployed at three sites in the Breton Sound

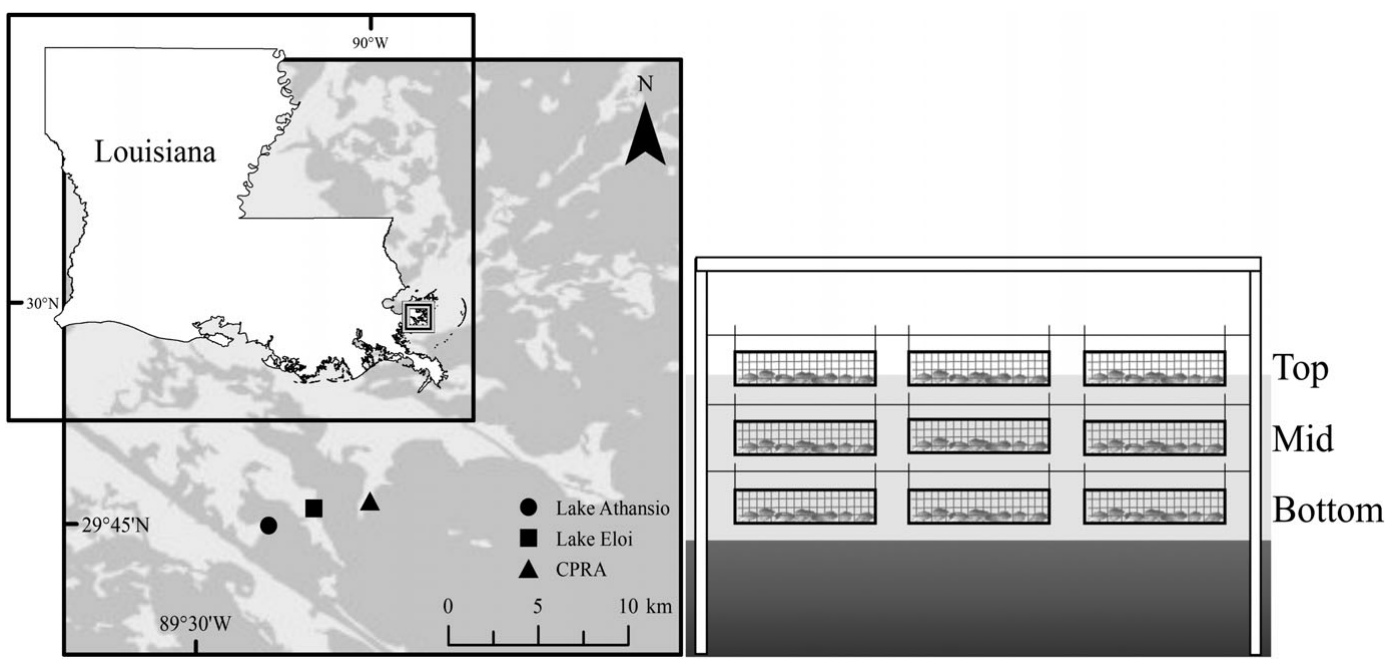

Figure 1. Map of study sites in southeastern Louisiana (circle=Lake Athanasio, square=Lake Eloi, triangle $=\mathrm{CPRA}$ ), with diagram of oyster ladder set up depicting top, mid, and bottom levels ( $40 \mathrm{~cm}$ difference between levels) of oyster bags filled with 20 clean oyster shells.

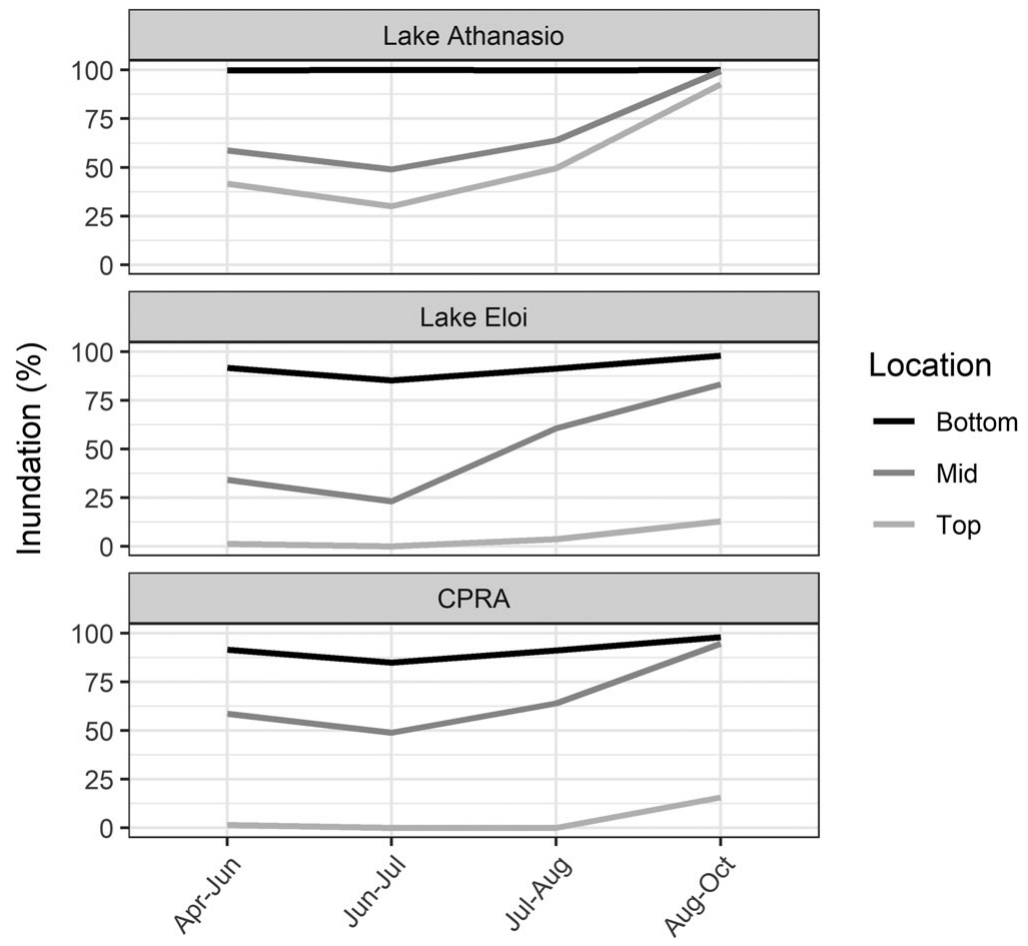

Figure 2. Percent of time oyster bags located at the bottom, mid, and top of each oyster ladder are inundated between sampling dates. 


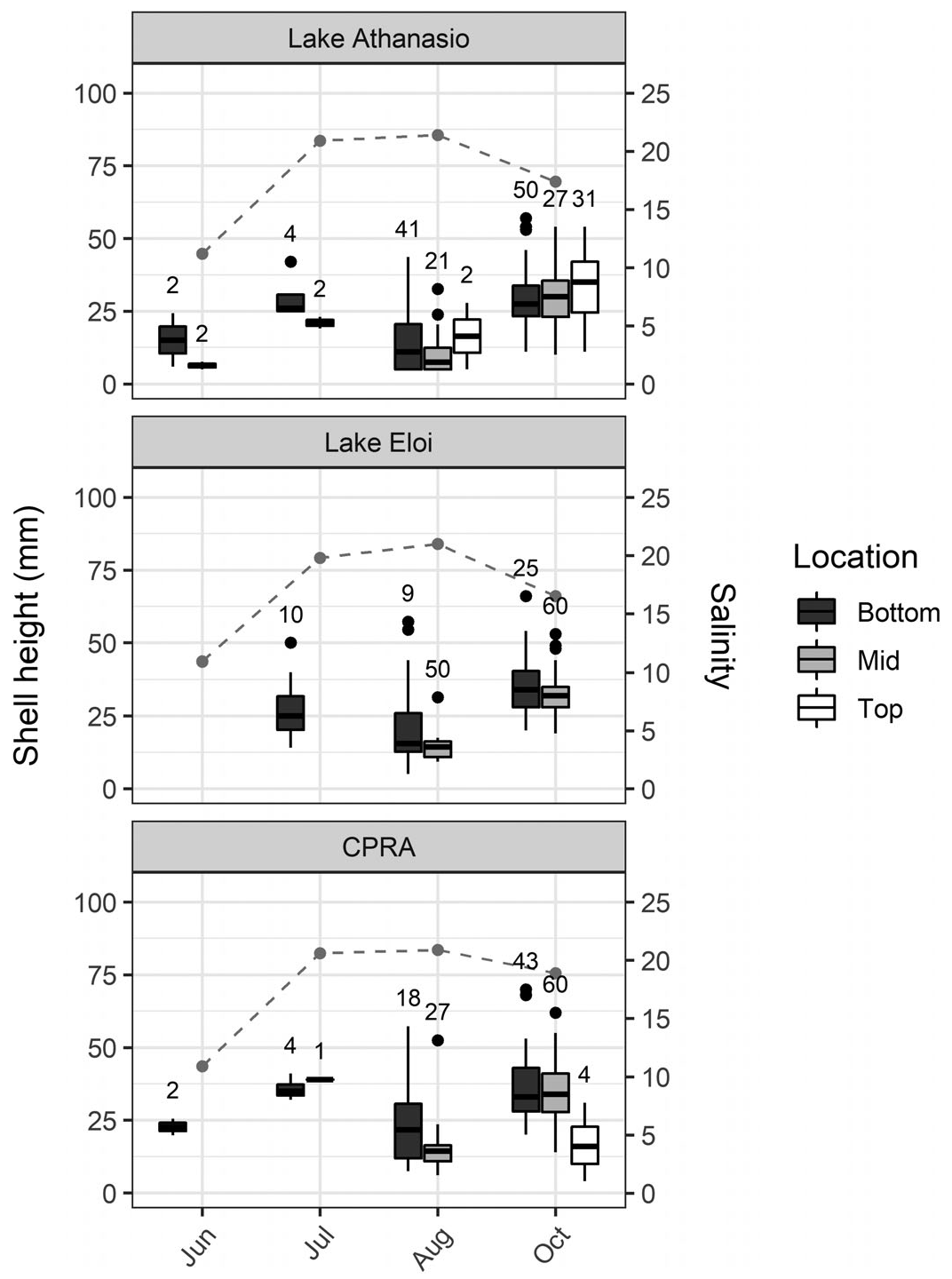

Figure 3. Boxplots of shell height $(\mathrm{mm})$ for each site by bag location (bottom, mid, top) and sampling date. The numbers above each box represent the total number of oysters measured. The boundaries of the box represent the 25 and $75 \%$ quantiles, while the line within the box is the median. Error bars above and below the box indicate $1.5^{\star} \mathrm{IQR}$ above and below the box boundaries, respectively. Salinity is represented by the gray dashed line and points.

Estuary, Louisiana, with three replicate oyster Australian longline bags (BST Oysters Supplies) per height ( 3 sites X 3 heights X 3 bags $=27$ bags). Approximately 20 cleaned, dried oyster shells were placed in each bag as substrate for recruitment. Distance from the sediment to the bottom of each oyster bag was measured, and the time and water level recorded. On June 4th, July 11th, August 26th, and October 30th, shell height $(\mathrm{mm})$ of live oysters was recorded (up to 20 oysters per bag). Salinity was measured in-situ with a YSI Pro2030.

Water level data were obtained from USGS recorder 0737452. Inundation (\%) was calculated using NOAA's Tidal Analysis Datum Calculator (https://access.co-ops.nos.noaa.gov/datumcalc/) for each site and height combination. 


\section{Results}

Prior to ladder deployment, salinity was below 10 from mid-March through June (109 days, USGS recorder 0737452 ), and $<5$ for the majority of that time (93 days). During the study period, inundation (\%) ranged from $30-100 \%$ for Lake Athanasio and 0-98\% for the Lake Eloi and CPRA sites (Figure 2, Supplementary Table S1). By the final sampling (October), total inundation (\%, mean \pm SE) across all sites was $22 \pm 17 \%$ at the top-level, $63 \pm 7 \%$ at the mid-level, and $95 \pm 3 \%$ at the bottom-level. Oysters recruited in the bags continuously through the study, with increased spat observed in the August and October samplings (Figure 3, Supplementary Table S1). Mean oyster shell height (mm) increased with inundation time (ANOVA with block on site, $\mathrm{p}<0.001$; Figure 3 ).

\section{Discussion}

Despite low salinities in the spring of 2018 resulting in very low spring and early summer recruitment, oyster ladders proved successful in capturing oyster growth at varying inundation levels. Similar to previous studies (e.g., Baillie \& Grabowski, 2019; Ridge et al., 2015, Solomon et al., 2014), oyster numbers and shell heights were consistently highest in the mid and bottom bags, which by the end of the study experienced $50-70 \%$, and $92-100 \%$ inundation across the sites, respectively. Longer, finer-scale (inundation levels, frequency of sampling) studies may show a threshold where oyster recruitment, growth, and mortality may be negatively impacted by predation or biofouling (Johnson \& Smee, 2014).

\section{Conclusion}

Identifying thresholds or ranges of exposure conducive to oyster growth on-reef will aid in designing and implementing intertidal oyster restoration, and living shorelines (e.g., Fuentes et al., 2019). Further studies examining variation and timing of exposure (i.e., absence of inundation), including seasonal patterns of exposure, may be equally important in explaining recruitment, growth, and mortality. These data enable scientists and restoration ecologists to improve ecological models that predict oyster performance under anticipated rising sea levels.

Acknowledgements. We thank Sam Moore, Eva Hillmann, Caleb Taylor, Rebecca Morris, Melanie Holton, and Scott Riley for field help. Any use of trade, firm, or product names is for descriptive purposes only and does not imply endorsement by the U.S. Government.

Author Contributions. DAM and MKL designed the study. DAM conducted data collection and statistical analyses. DAM and MKL wrote the article.

Funding Information. This research was supported by funding from Louisiana Department of Wildlife and Fisheries through support to the Louisiana Fish and Wildlife Cooperative Research Unit, and from the Louisiana Coastal Protection and Restoration Authority.

Data Availability Statement. Data used in this study are available in supplementary materials (Supplementary Table S1).

Conflict of Interest. DAM and MKL declare none.

Supplementary Materials. To view supplementary material for this article, please visit http://dx.doi.org/10.1017/exp.2020.35.

\section{References}

Baillie, C. J., \& Grabowski, J. H. (2019). Factors affecting recruitment, growth and survival of the eastern oyster Crassostrea virginica across an intertidal elevation gradient in southern New England. Marine Ecology Progress Series, 609, $119-132$.

Bishop, M. J., \& Peterson, C. H. (2006). Direct effects of physical stress can be counteracted by indirect benefits: Oyster growth on a tidal elevation gradient. Oecologia, 147, 426-433.

Blomberg, B. N., Beseres Pollack, P., Montagna, P. A., \& Yoskowitz, D. W. (2018). Evaluating the U.S. Estuary Restoration Act to inform restoration policy implementation: A case study focusing on oyster reef projects. Marine Policy, 91, 161-166.

Fodrie, J. F., Rodriguez, A. B., Baillie, C. J., Brodeur, M. C., Coleman, S. E., Gittman, R. K., Keller, D. A., Kenworthy, M. D., Poray, A. K., Ridge, J. T., Theuerkauf, E. J., \& Lindquist, N. L. (2014). Classic paradigms in a novel environment: Inserting 
food web and productivity lessons from rocky shores and saltmarshes into biogenic reef restoration. Journal of Applied Ecology, 51, 1314-1325.

Fuentes, C. M., Whitcraft, C. R., \& Zacherl, D. C. (2019). Adaptive restoration reveals potential effect of tidal elevation on oyster restoration outcomes. Wetlands, 40, 93-99. https://doi.org/10.1007/s13157-019-01166-7.

Johnson, K. D., \& Smee, D. L. (2014). Predators influence the tidal distribution of oysters. Marine Biology, 161, $1557-1564$.

La Peyre, M. K., Aguilar Marshall, D., Miller, L. S., \& Humphries, A. T. (2019). Oyster reefs in northern Gulf of Mexico estuaries harbor diverse fish and decapod crustacean assemblages: A meta-synthesis. Frontiers in Marine Science, 6, 666.

National Oceanic and Atmospheric Administration (NOAA). (2020). Commercial fisheries statistics, annual landings. https:// foss.nmfs.noaa.gov.

Ridge, J. T., Rodriguez, A. B., Fodrie, J. F., Lindquist, N. L., Brodeir, M. C., Coleman, S. E., Grabowski, J. H., \& Theuerkauf, E. J. (2015). Maximizing oyster-reef growth supports green infrastructure with accelerating sea-level rise. Scientific Reports, $\mathbf{5}$, 14785 .

Solomon, J. A., Donnelly, M. J., \& Walters, L. J. (2014). Effects of sea level rise on the intertidal oyster Crassostrea virginica by field experiments. Journal of Coastal Research, 68, 57-64.

Cite this article: Marshall DA, La Peyre MK (2020). Effects of inundation duration on southeastern Louisiana oyster reefs Experimental Results, 1, e30, 1-8. https://doi.org/10.1017/exp.2020.35 


\section{Peer Reviews}

\section{Reviewing editor: Dr. Keith Walters}

Coastal Carolina University, Department of Marine Science, P.O. Box 261954, Conway, South Carolina, United States, 29528$6054,843-349-2545$

This article has been accepted because it is deemed to be scientifically sound, has the correct controls, has appropriate methodology and is statistically valid, and met required revisions.

doi:10.1017/exp.2020.35.pr1

\section{Review 1: Effects of inundation duration on southeastern Louisiana oyster reefs \\ Reviewer: Dr. Linda Walters}

University of Central Florida, Orlando, United States, 32816-2368

Date of review: 12 April 2020

(C) The Author(s), 2020. Published by Cambridge University Press This is an Open Access article, distributed under the terms of the Creative Commons Attribution licence (http://creativecommons.org/licenses/by/4.0/), which permits unrestricted re-use, distribution, and reproduction in any medium, provided the original work is properly cited.

Conflict of interest statement. I participate in a large oyster research group ( 25 scientists) which includes Dr. LaPeyre. I do not know her personally and this consider myself to have no conflict of interest.

Comments to the Author: Many intertidal oyster restoration efforts depend on natural recruitment. At a local scale, this requires knowledge of the inundation levels, and, as the authors state, even a few centimeters of height can be the difference between a successful and a failed restoration project. The authors of this project examined natural oyster recruitment on oyster shell deployed at three inundation heights in three locations in Louisiana. They found recruitment was greatest at their highest tested inundation level ( $89+\%$ inundation). Future additions to this project could include testing additional inundation levels to further improve chances for success with restoration, and tracking mortality over time as seasonal fluctuations in water levels may be a confounding variable for long-term success.

\section{Score Card}

Presentation

Is the article written in clear and proper English? (30\%)

Is the data presented in the most useful manner? (40\%)

Does the paper cite relevant and related articles appropriately? (30\%)

\section{Context}

Does the title suitably represent the article? (25\%)

Does the abstract correctly embody the content of the article? (25\%)

Does the introduction give appropriate context? (25\%)

Is the objective of the experiment clearly defined? (25\%) 
Are the limitations of the experiment as well as the contributions of the experiment clearly outlined? (20\%) 


\section{Review 2: Effects of inundation duration on southeastern Louisiana oyster reefs}

Reviewer: Dr. Kathryn O'Shaughnessy (D)

Texas Parks and Wildlife Department, Austin, Texas, United States, 78744

Date of review: 10 May 2020

(C) The Author(s), 2020. Published by Cambridge University Press This is an Open Access article, distributed under the terms of the Creative Commons Attribution licence (http://creativecommons.org/licenses/by/4.0/), which permits unrestricted re-use, distribution, and reproduction in any medium, provided the original work is properly cited.

Conflict of interest statement. Reviewer declares none

Comments to the Author: This paper looks at recruitment and growth of oysters at three inundation levels using oyster ladders. Number of oysters and growth rate were greatest under conditions of longer inundation periods. This will be a valuable addition to the literature. The reviewer has just a small number of comments: (1) What were the controls? (2) What were the limitations of the study? (3) Please provide a description or reference for NOAA's Inundation Analysis Tool. (4) Considering choosing either imperial or metric units but not both in the same piece of work.

\section{Score Card}

Presentation

5.0

Is the data presented in the most useful manner? $(40 \%)$

Does the paper cite relevant and related articles appropriately? (30\%)
Context

5.0

Does the title suitably represent the article? (25\%)

Does the abstract correctly embody the content of the article? (25\%)

Does the introduction give appropriate context? (25\%)

Is the objective of the experiment clearly defined? (25\%)

Analysis
Are the limitations of the experiment as well as the contributions of the experiment clearly outlined? $(20 \%)$ 